\title{
Treatment of Compound Melanocytic Nevus Using a Long-pulsed 755-nm Alexandrite Laser
}

Young Koo Kim ${ }^{1}$

Sung Bin $\mathrm{Cho}^{2}$

1Yonsei Star Skin \& Laser Clinic, Seoul, Korea
${ }^{2}$ Department of Dermatology and Cutaneous
Biology Research Institute, Yonsei University
College of Medicine, Seoul, Korea

Received June 3, 2013

Revised June 10, 2013

Accepted June 10, 2013

\section{Correspondence}

Sung Bin Cho

Department of Dermatology and Cutaneous Biology Research Institute, Yonsei University College of Medicine, 50, Yonsei-ro, Seodaemungu, Seoul 120-752, Korea

Tel: $+82-2-2228-2080$

Fax: +82-2-393-9157

E-mail: drsbchođggmail.com

(c) Korean Society for Laser Medicine and Surgery

(c) This is an open access article distributed under the terms of the Creative Commons Attribution NonCommercial License (http://creativecommons.org/ licenses/by-nc/3.0) which permits unrestricted noncommercial use, distribution, and reproduction in any medium, provided the original work is properly cited.
We herein report a 16-year-old Korean male patient with darkly pigmented mammillated compound melanocytic nevus effectively treated by a 755$\mathrm{nm}$ alexandrite laser with a pulse duration of $3 \mathrm{msec}$. Pigment-specific lasers are known to be effective in the treatment of acquired and congenital melanocytic nevi as they mainly target the chromophores of melanin pigments in nevus cells. In the present report, we proposed the use of an integrated dynamic cooling device that effectively protected the epidermis and facilitated safer delivery of high pulse energy of sufficient intensity to destroy large nests of compound nevus cells. Furthermore, a $755-\mathrm{nm}$ alexandrite laser with a pulse duration of $3 \mathrm{msec}$ shortened procedure times compared to conventional resurfacing lasers by eliminating the risk of post-therapy oozing or bleeding with selective photothermolysis, in addition to targeting a larger spot size.

\section{Key words}

Long-pulsed alexandrite laser; Compound melanocytic nevus; Asian skin 


\section{INTRODUCTION}

Common acquired melanocytic nevi (AMNs) and small to medium-sized congenital melanocytic nevi (CMNs) are commonly treated with resurfacing laser devices, such as 10,600-nm carbon dioxide and 2,940-nm erbium:yttriumaluminum-garnet (YAG) lasers. ${ }^{1-3}$ Lasers with selective photothermolysis are known to be effective against AMNs and CMNs by targeting the chromophores of melanin pigments in such lesions. Studies on pigmentspecific lasers in treatment of AMNs and CMNs have suggested that junctional nevus can be effectively treated with $Q$-switched pigment lasers and that longer-pulsed pigment lasers are effective in treating $\mathrm{CMN}$. $^{1-5}$

Wang et al. ' demonstrated that satisfactory treatment outcomes were achieved via a single session of 755-nm alexandrite laser treatment with a pulse duration of 100 $\mu \mathrm{sec}$ for small junctional nevus in Asian patients. Here, we report a case of darkly-pigmented and mammillated compound melanocytic nevus effectively treated by a 755$\mathrm{nm}$ alexandrite laser with a pulse duration of $3 \mathrm{msec}$.

\section{CASE REPORT}

A 16-year-old Korean male patient presented with a black papule with thick hairs on the perioral area. The lesion had appeared as a child and had slowly enlarged and darkened over the past several years. He had no pertinent family history or medical history. Upon examination, a black mammillated papule with centrally located thick hairs was seen on the perioral area (Fig. 1A). Dermoscopic examination revealed no remarkable findings suggestive of malignant transformation. The pigmented lesion was clinically diagnosed as compound melanocytic nevus; the patient had never been treated for this skin condition before.

After obtaining informed consent, he was treated with four sessions of long-pulsed 755-nm alexandrite laser (GentleMax; Candela, Wayland, MA, USA) therapy at onemonth intervals. Topical EMLA cream leutectic mixture of 2.5\% lidocaine $\mathrm{HCl}$ and 2.5\% prilocaine; AstraZeneca AB, Södertälje, Sweden) was applied as a local anaesthetic one hour prior to laser therapy. The lesion was treated with the settings of a 3 msec-pulse width, $35 \mathrm{~J} / \mathrm{cm}^{2}$, a
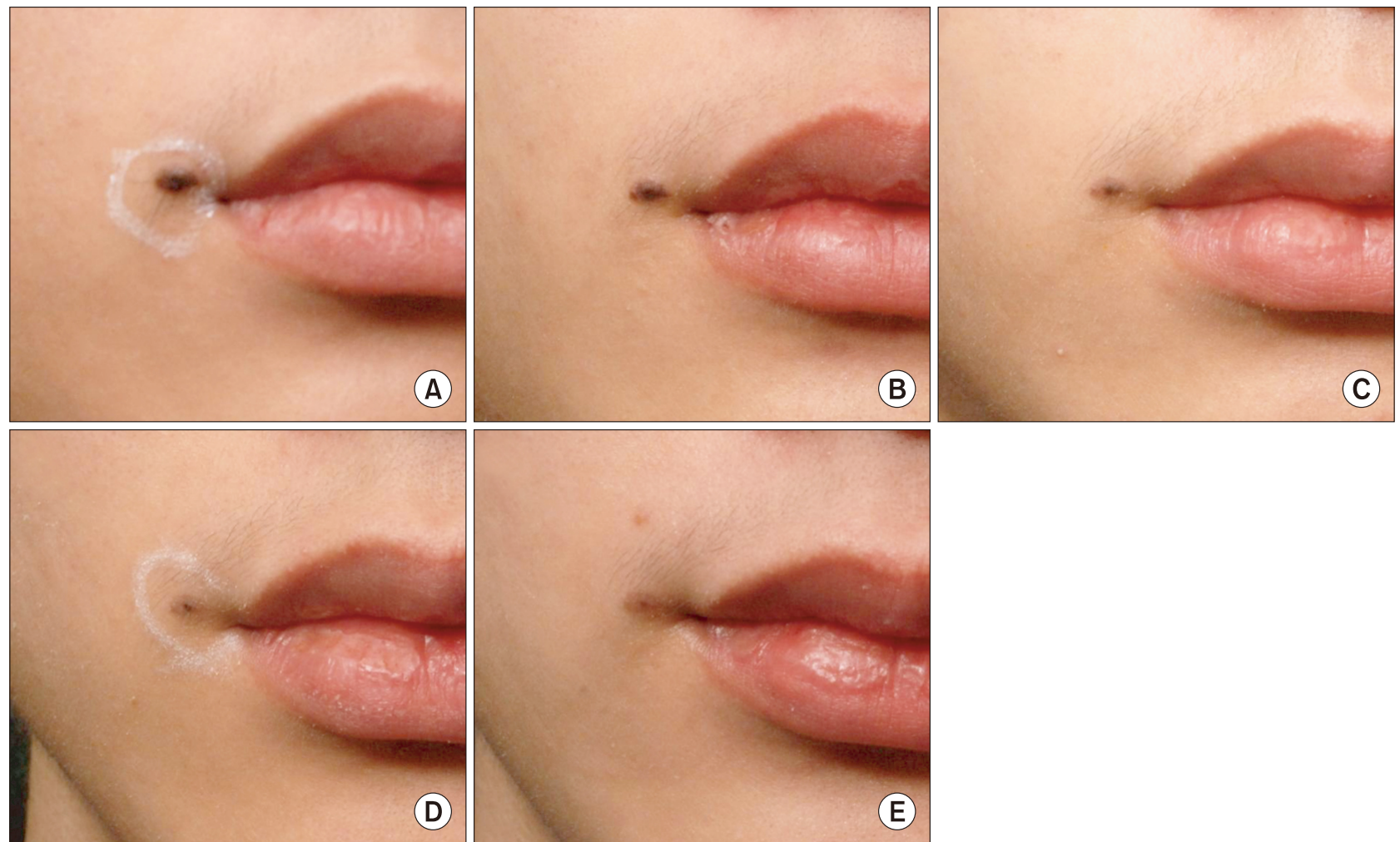

Fig. 1. A black mammillated compound nevus with centrally located thick hairs (A) before and (B) one month after the first session, (C) one month after the second session, (D) one month after the third session, and (E) one month after the final session of long-pulsed 755-nm alexandrite laser treatment. 
$6 \mathrm{~mm}$-spot size, and two passes, creating fine bubbles on the irradiated lesion. A dynamic cooling device with a setting of 0/0/30 (pre-irradiation cooling/delay/ post-irradiation coolingl msec was applied to cool the epidermis. The compound nevus became crusted soon after the long-pulsed alexandrite laser treatment, and the crust spontaneously subsided within 5 to 7 days. The patient was advised to avoid rubbing, excessive washing, and sunlight overexposure to the treated area. He was also instructed to apply a broad-spectrum sunscreen thereto after the crusting peeled off.

Marked clinical improvement was observed from the second therapy session (Fig. 1B-D), and at one month after the final treatment, the compound nevus had remarkably been disappeared (Fig. 1E). No side effects of post-therapy blister formation, secondary bacterial or viral infection, post-therapy prolonged erythema, dyschromia, or scarring, were recorded.

\section{DISCUSSION}

Here, we report a case of darkly-pigmented mammillated compound melanocytic nevus effectively treated by four sessions of 755-nm alexandrite laser therapy with a pulse duration of $3 \mathrm{msec}$. We discerned that an integrated dynamic cooling device effectively protected the epidermis and facilitated safer delivery of high pulse energy great enough to destroy large nests of compound nevus cells. Additionally, selective photothermolysis, eliminating the risk of post-therapy oozing or bleeding, as well as the use of a larger spot size, seemed to conveniently shorten procedure times compared to conventional resurfacing lasers.

Pigment-specific long-pulsed lasers have been shown to be effective and safe in treating pigment lesions by irradiating with $\mu \mathrm{sec}$ to msec-pulse-width laser energies. ${ }^{6-9}$ August et al. ${ }^{2}$ reported that Q-switched pigmentspecific lasers were unable to lighten mammillated CMN and offered no significant benefit over treatment with a carbon dioxide laser. However, large nests of nevi cells in CMN can be effectively destructed by highenergy fluencies of ruby laser with pulse durations of 1 to $300 \mathrm{msec}^{6}{ }^{6}$ We suggested that the $755-\mathrm{nm}$ alexandrite laser therapy with a pulse duration of $3 \mathrm{msec}$ might have targeted not only melanin pigments, but also large nests of nevi cells in our case.

In Asians, long-pulsed 532-nm neodymium (Nd):YAG laser treatment with a pulse duration of $2 \mathrm{msec}$ demonstrated equivalent clinical efficacies in treatment of facial lentigines, as well as a significantly lower risk of side effects, to a Q-switched 532-nm Nd:YAG laser.7 A prospective split-face study also reported that a longpulsed alexandrite laser with a 100 msec-pulse width lead to effective clinical outcomes for freckles and lentigines, similar to a Q-switched alexandrite laser with a 50 nsec-pulse width, but the long-pulsed alexandrite laser presented with remarkably fewer adverse events. ${ }^{10}$

In conclusion, we suggest that a long-pulsed 755-nm alexandrite laser may be of use in treating compound nevus as a new treatment modality in some patients. In this therapy, side effects associated with resurfacing lasers and pigment-specific lasers, especially posttherapy dyschromia and scarring in Asian skin, can be minimized. However, optimized, prospective studies should be conducted in the future to confirm our findings.

\section{REFERENCES}

1. Wang EC, Sen P, Goh CL, Chua SH. Single treatment with 100-microsecond alexandrite laser clears selected acquired melanocytic nevi in type IV Asian facial skin. J Cutan Aesthet Surg 2013;6:21-6.

2. August PJ, Ferguson JE, Madan V. A study of the efficacy of carbon dioxide and pigment-specific lasers in the treatment of medium-sized congenital melanocytic naevi. Br J Dermatol 2011;164:1037-42.

3. Polder KD, Landau JM, Vergilis-Kalner IJ, Goldberg LH, Friedman PM, Bruce S. Laser eradication of pigmented lesions: a review. Dermatol Surg 2011;37:572-95.

4. Kilmer SL. Laser eradication of pigmented lesions and tattoos. Dermatol Clin 2002;20:37-53

5. Duke D, Byers HR, Sober AJ, Anderson RR, Grevelink JM. Treatment of benign and atypical nevi with the normal-mode ruby laser and the $\mathrm{Q}$-switched ruby laser: clinical improvement but failure to completely eliminate nevomelanocytes. Arch Dermatol 1999;135:290-6.

6. Ueda S, Imayama S. Normal-mode ruby laser for treating congenital nevi. Arch Dermatol 1997;133:355-9.

7. Chan HH, Fung WK, Ying SY, Kono T. An in vivo trial comparing the use of different types of $532 \mathrm{~nm} \mathrm{Nd:YAG} \mathrm{lasers} \mathrm{in} \mathrm{the}$ treatment of facial lentigines in Oriental patients. Dermatol Surg 2000;26:743-9.

8. Rosenbach A, Lee SJ, Johr RH. Treatment of medium-brown solar lentigines using an alexandrite laser designed for hair reduction. Arch Dermatol 2002;138:547-8.

9. Trafeli JP, Kwan JM, Meehan KJ, Domankevitz Y, Gilbert S, Malomo K, et al. Use of a long-pulse alexandrite laser in the treatment of superficial pigmented lesions. Dermatol Surg 
2007;33:1477-82.

10. Ho SG, Yeung CK, Chan NP, Shek SY, Chan HH. A comparison of $\mathrm{Q}$-switched and long-pulsed alexandrite laser for the treatment of freckles and lentigines in oriental patients. Lasers Surg Med 2011;43:108-13. 